\title{
Comments on the use of a deep tank in planktological research
}

\author{
R. J. Conover \& M. A. Paranjape \\ Department of the Environment, Fisheries and Marine Service, \\ Marine Ecology Laboratory, Bedford Institute of Oceanography; \\ Dartmouth, Nova Scotia, Canada
}

\begin{abstract}
The Dalhousie University Aquatron tower tank $(10 \mathrm{~m}$ deep, $3.66 \mathrm{~m}$ in diameter, with viewing ports at regular intervals down its side) can be operated in a continuous flow mode or as a closed system and has programmable illumination providing up to $10 \%$ of maximum summer illumination at the surface. Such systems have several drawbacks. Perhaps most serious is the lack of an adequate control. In the continuous flow mode the system is subject to the same type of sampling error encountered in the use of any other sampling device in a patchy environment. Temperature regulation and mixing were a problem with the tank in the static mode. As a result considerable stratification of properties occurred. Irradiance seemed to have too much directionality for normal diel migration patterns to develop in the zooplanktonic community. On the other hand, the system would seem very useful for short-term studies of behaviour and community interaction. For example, the pteropod Spiratella retroversa has been observed to regulate its buoyancy almost instantly. Typically animals remain motionless or slowly sinking $\left(5-20 \mathrm{~cm} \mathrm{~min}^{-1}\right)$ for 1 to 5 minutes, swim up for 10 to $60 \mathrm{~s}$, and then return to "resting" and feeding. Mixed zooplankton populations, including such notoriously delicate animals as Sagitta elegans, can also be maintained and behaviour studied. Despite a variable temperature regime, the structure of the zooplankton community remained intact for more than three months.
\end{abstract}

\section{INTRODUCTION}

The non-random and constantly changing distribution of physical, chemical and biological properties of aquatic environments significantly influences the quality of many types of biological observations made in the field. Similarly, laboratory observations of biological events must often be interpreted with caution because of the uncertain effects of the boundary conditions associated with small systems. As a compromise, intermediate sized volumes of water in "big bags" (Takahashi et al., 1975) or large, shore-based installations (Strickland et al,, 1969) have recently received considerable attention. The Aquatron facility of Dalhousie University (Halifax, Nova Scotia, Canada) has recently been formally opened (September 20, 1974)

* Bedford Institute of Oceanography Contribution. 
and the following account represents some preliminary observations emphasizing the advantages and disadvantages of such a system as a simulator of the natural ecosystem.

\section{DESCRIPTION OF THE AQUATRON TOWER TANK}

As shown in Figure 1, the tank is somewhat more than $10 \mathrm{~m}$ deep, $3.66 \mathrm{~m}$ in diameter with viewing and sampling ports at regular intervals down its side. It is made of concrete with a non-toxic PVC lining. Sea water entering the system is taken from near the bottom (ca. $15 \mathrm{~m}$ depth) in Northwest Arm, a small inlet adjacent to Halifax Harbor. Water may be introduced at several levels in the tank either before

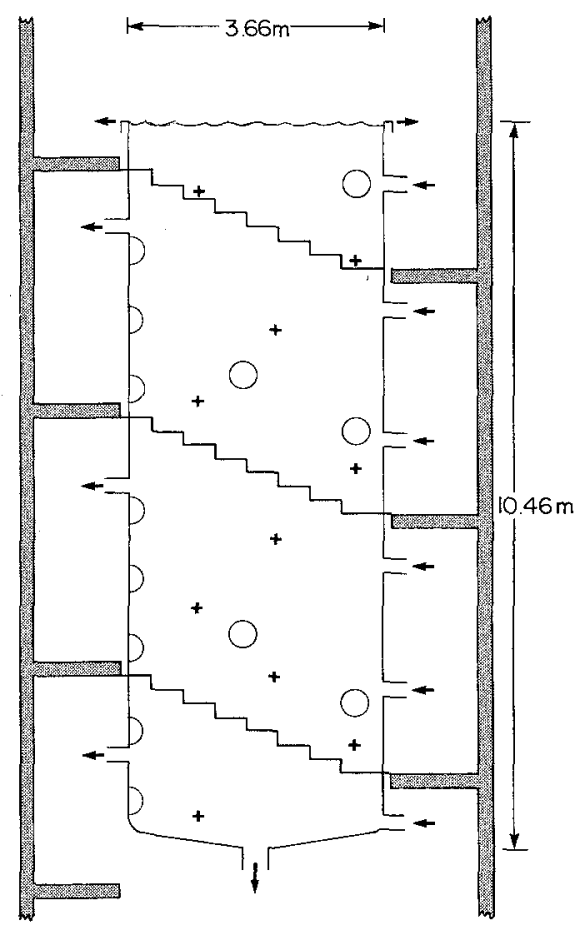

Fig. 1: The Dalhousie University Aquatron tower tank showing the arrangement of viewing ports (circles), sampling ports (crosses), and incurrent and excurrent piping for filling, emptying and recycling the tank

or after filtration and allowed to run to waste or the system may be closed and recirculated through filters (Fig. 2). At the time of our observations, the refrigeration and heat exchange components were not operational. A winch and sampling platform facilitate the making of remote observations. A programmable battery of mercury vapor lamps provide irradiance up to $10 \%$ of maximum summertime levels at the surface at this latitude. 


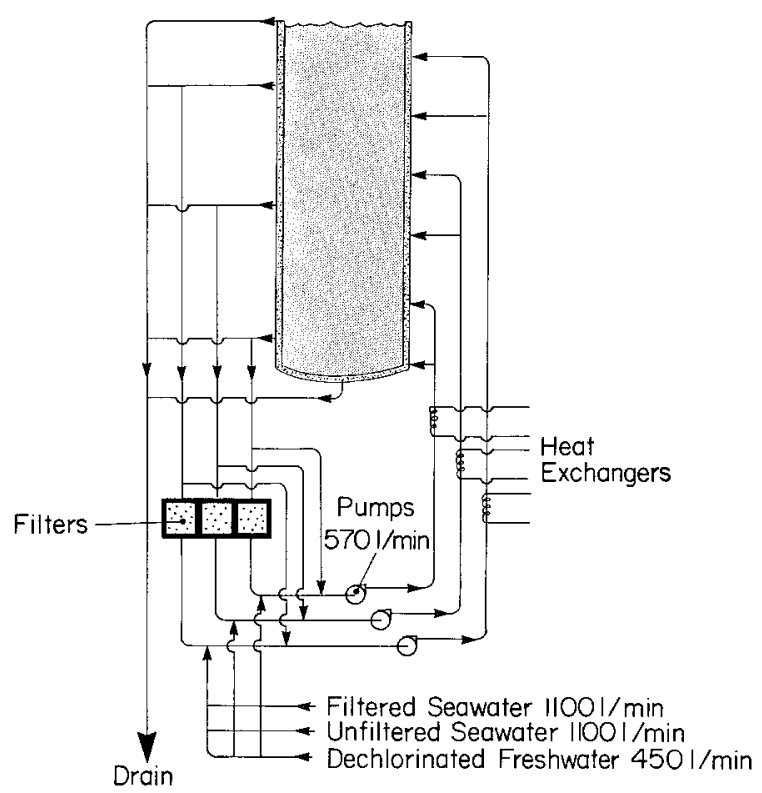

Fig. 2: Diagrams of the arrangement of piping, including filters, pumps and heat exchangers, servicing the tower tank

\section{METHODS}

For the most part, sampling was carried out with standard equipment and techniques using water bottles of the Niskin type, a $1 / 2$ metre diameter plankton net of $76 \mu \mathrm{m}$ mesh towed vertically, a $2^{\prime \prime}$ submersible pump (Tsurumi $400 \mathrm{BB}$ ), and a Beckman RS 5 salinity-temperature probe. In using the pump for zooplankton sampling, water was passed through $76 \mu \mathrm{m}$ mesh into a tank of $109 \mathrm{l}$ capacity and the time of filling recorded. Flow rate, which was usually around $1751 \mathrm{~min}^{-1}$, was then used to calculate the time to filter at least $0.5 \mathrm{~m}^{3}$ of water. Sediment traps of the sort employed by Webster et al. (1975) were installed at the bottom to estimate zooplankton mortality and losses of particulate matter from the water column.

In addition to temperature and salinity, routine observations included chlorophyll and phaeopigments, following the fluorescent method first used by Yentsch \& Menzel (1963), particulate carbon and nitrogen using an F \& M 185 CHN analyzer, and particle volume as estimated with a Model T Coulter Counter.

Experiments were carried out with the tank in the continuous flow mode (rate generally between 60 and $901 \mathrm{~min}^{-1}$ ) or completely static. Observations were made on the natural population introduced into the tank through its circulation system and on populations introduced into the tank after concentration by plankton nets. 


\section{RESULTS}

The initial purpose of our experiments was to establish in the tower tank populations of certain larger planktonic animals, such as pteropods, euphausiids and chaetognaths, which do not easily adapt to laboratory conditions, in order to study their feeding behaviour visually and hopefully to measure feeding rate and growth as well. However, it soon became obvious that the particulate environment in the tank, presumably of importance as a food source for the animals being studied, could not be easily controlled. Table 1 illustrates one aspect of the problem. Samples taken from

Table 1

Comparison of water in the tower tank with that near its source and that actually entering the system, February 20,1976. Water entering the tank near the bottom

\begin{tabular}{|c|c|c|c|c|c|c|c|}
\hline \multirow[b]{2}{*}{ Location } & \multirow[b]{2}{*}{ Time } & \multirow{2}{*}{$\begin{array}{c}\text { Depth } \\
(\mathrm{m})\end{array}$} & \multirow{2}{*}{$\begin{array}{c}\text { Particle } \\
\text { volume } \\
\text { (ppm) }\end{array}$} & \multicolumn{4}{|c|}{ Particulate matter $\left(\mu \mathrm{g} 1^{-1}\right)$} \\
\hline & & & & Carbon & Nitrogen & $\begin{array}{l}\text { Chloro- } \\
\text { phyil }\end{array}$ & $\begin{array}{c}\text { Phaeo- } \\
\text { pigment }\end{array}$ \\
\hline \multirow{3}{*}{$\begin{array}{l}\text { Northwest } \\
\text { arm near } \\
\text { intake }\end{array}$} & Between & 10 & 1.522 & 168 & 23 & 0.35 & 0.60 \\
\hline & $0930 \&$ & 15 & 1.451 & 158 & 24 & 0.33 & 0.56 \\
\hline & 1130 & 16 & 1.597 & 164 & 25 & 0.23 & 0.76 \\
\hline \multirow{2}{*}{$\begin{array}{l}\text { Tower } \\
\text { tank inlet }\end{array}$} & 0930 & - & 1.008 & 166 & 23 & 0.09 & 0.72 \\
\hline & 1130 & - & 0.379 & 78 & 14 & 0.04 & 0.17 \\
\hline \multirow{3}{*}{$\begin{array}{l}\text { Tower } \\
\text { tank }\end{array}$} & 1445 & 1 & 0.429 & 101 & 16 & 0.03 & 0.23 \\
\hline & 1500 & 5 & 0.696 & 96 & 15 & 0.07 & 0.33 \\
\hline & 1515 & 10 & 0.548 & 92 & 15 & 0.05 & 0.28 \\
\hline
\end{tabular}

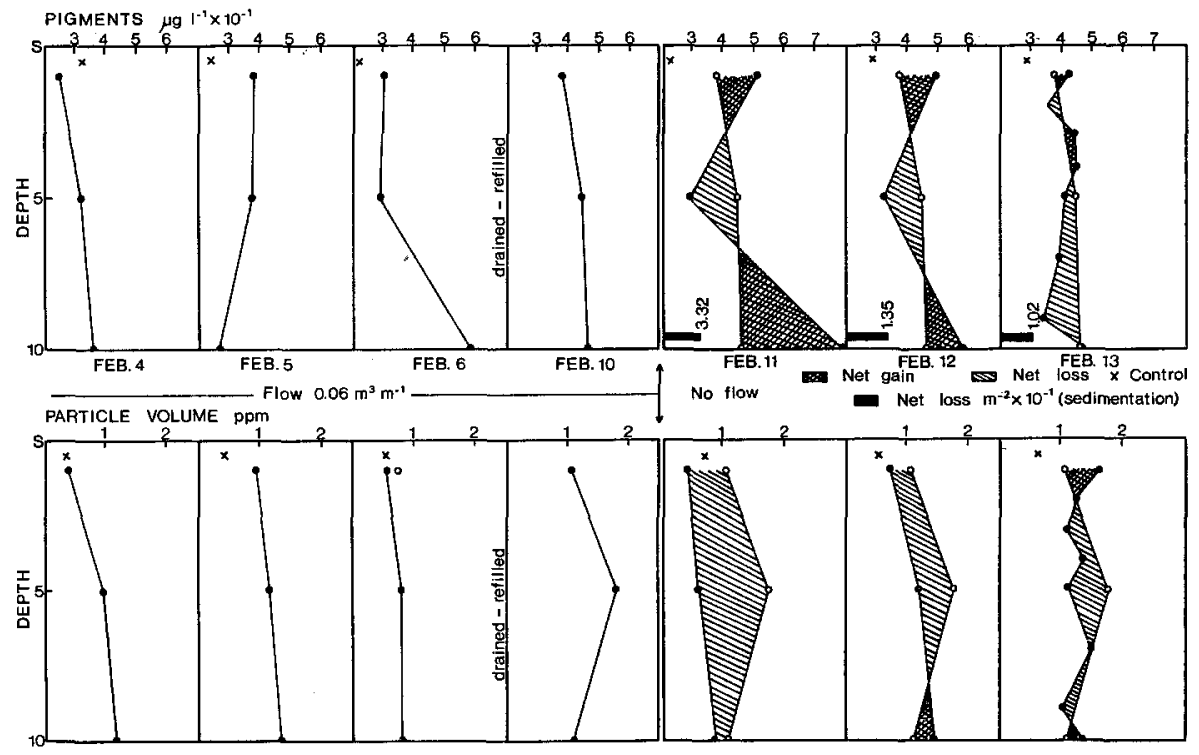

Fig. 3: Vertical distribution of pigments and particle volumes in the tower tank in the continuous flow (left) and non-flow modes (right) 
the bottom water near the intake showed considerably higher concentrations of all parameters measured than water entering the tank (inlet) or in the tank. Judging from samples taken at the inlet about two hours apart, water entering the system is subject to the same kinds of sampling errors that have plagued oceanographers for years. There may also have been destruction of chlorophyll in the passage through the plumbing but this is not certain with so few samples for comparison.

Perhaps rather naively we hoped that by sampling from the inlet and outflow with the system in the continuous flow mode that we might gain information on

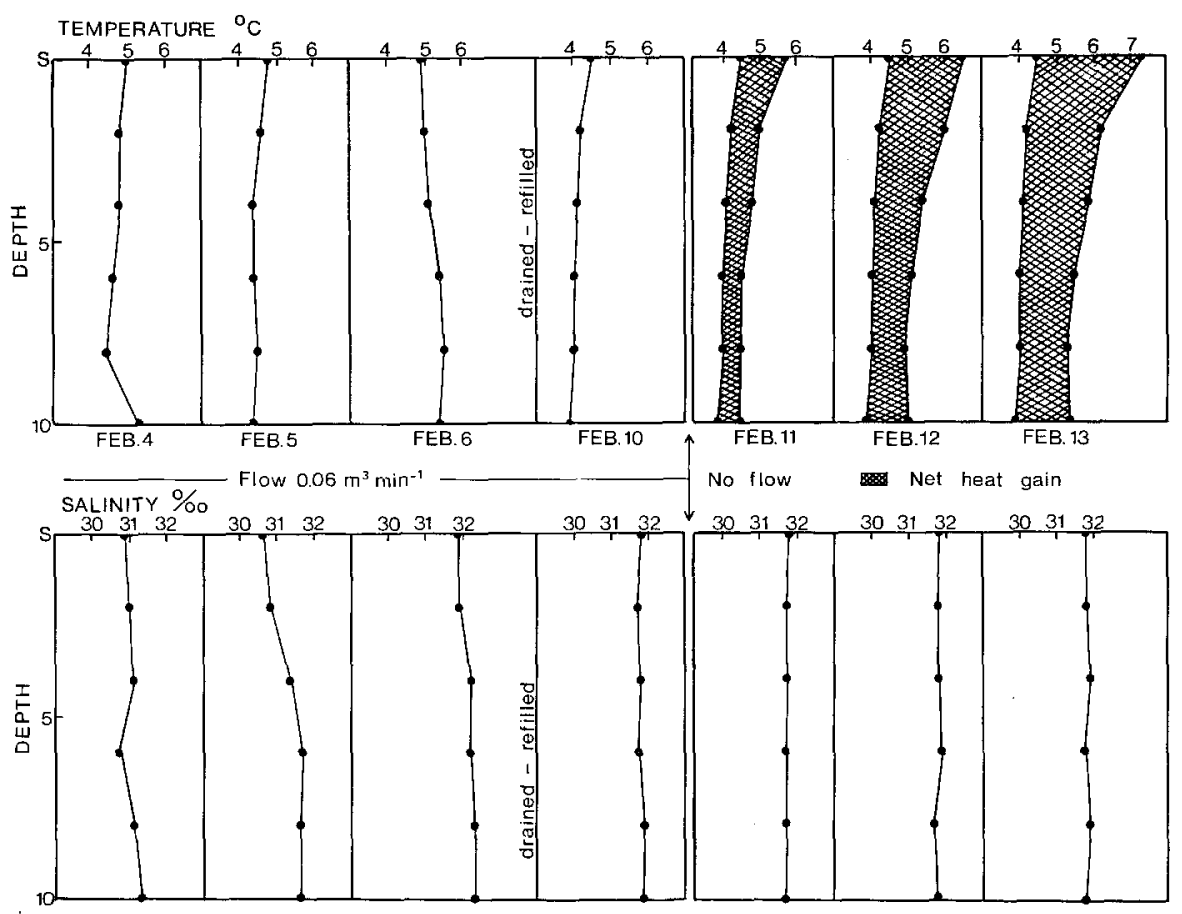

Fig. 4: Vertical distribution of temperature and salinity in the tower tank in the continuous flow (left) and non-flow modes (right)

events occurring in the tank. However, day to day variations such as those shown in Figure 3 exceeded inflow-outflow differences. We also tried a suspended glass carboy in the tank as a control (crosses in Fig. 3) but events inside and outside these containers bore little resemblance to each other.

When the system was closed (right side of Figs. 3 and 4) the variance in certain components was reduced but warming of the tank was pronounced even though it apparently proceeded in a regular fashion (Fig. 4). Without the mixing affect of water exchange, considerable particulate matter settled out (Fig. 3).

On February 13 detailed sampling of all components was undertaken using the pump (Fig. 5). Stratification of certain particulate components apparently has taken 
place. We noticed several times localized blooms of flagellates or tintinnids. Samples hand collected from very dense patches of flagellates right at the surface yielded particle volumes up to $760 \mathrm{ppm}$.

The zooplankton distributions shown in Figure 5 are perhaps the most interesting of the patterns observed and seem to reflect relatively well what we know of the distribution of the three dominant copepod species in Bedford Basin during winter

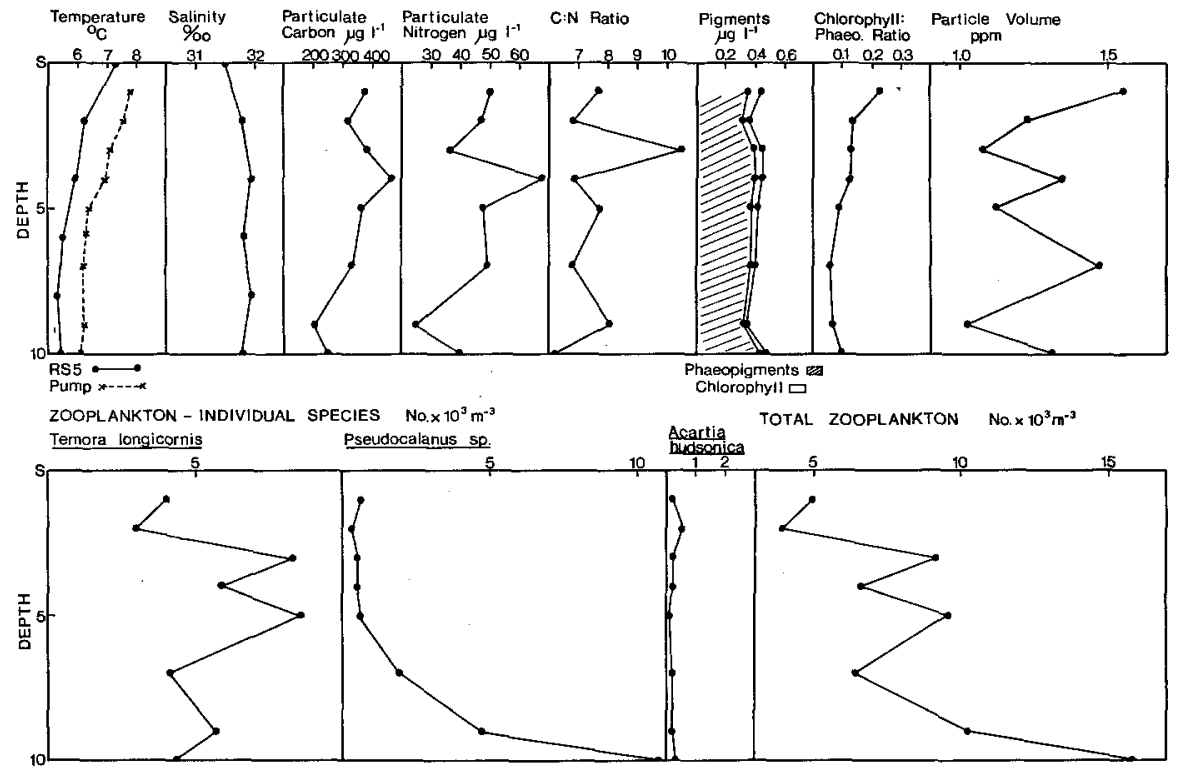

Fig. 5: Detailed vertical distribution of temperature, salinity, particulate carbon, particulate nitrogen, chlorophyll, phaeopigments, particle volume, total zooplankton, and for three individual species on February 13, 1976 with tank in the non-flow mode

(Conover \& Mayzaud, 1976). At the same time they suggest that the pump could yield a variety of estimates of biomass depending on the choice of depth sampled, disregarding completely the question of escapement.

To compare the effectiveness of the pump and vertical net tows as samplers of mean biomass, a Wilcoxon matched-pairs signed-ranks test (Siegel, 1956) was carried out on ten sets of data. While the vertical tows on average yielded higher numbers per unit volume the differences were not significant.

One other source of error in using the vertical net was also detected. Visual observation suggested that the larger organisms seemed to be near the tank edge rather than being uniformly distributed across its diameter. A set of comparative tows taken on April 9, 1976 confirmed that nearly 4 times more zooplankton were near the edge than in the center, a pattern shown by every important category of plankton.

The neritic plankton animals did not usually seem to show marked differences in vertical distribution between "day" and "night", as imposed by the tank's programmed illumination. On one occasion there appeared to be a reverse migration with 
daytime surface concentrations perhaps becoming more uniformly dispersed through the water column after the lights turned off. However, considerably more work should be done to determine the possible usefulness of such a water column in the study of zooplankton migatory patterns.

In two regards the tank proved potentially very useful. Populations of zooplankton animals, including pteropods, euphausiids, and chaetognaths, survived in the tank and at least some net secondary production took place. Secondly, the large animals were clearly visible through the tank ports and certain aspects of their behaviour could be studied.

In the winter of 1976 we introduced a typical neritic zooplankton population taken by net tows from Bedford Basin into the tank and followed its behaviour more or less continuously until it was accidently destroyed at the end of May. As shown in Figure 6, the temperature increased relatively steadily over the first three weeks of observation. However, the animal populations also seemed to increase in total numbers and there was no major shift in composition. Over the first 10 days there was a general loss of older stages of copepods to the sediment traps (Fig. 6) but concommittant increase in nauplii and younger stages, as shown in Figure 7, which yielded a net increase in the total population.

By actual numbers the populations introduced into the tank contained $6.7 \%$ Sagitta elegans, mostly mature individuals. While there was a steady decline in numbers of adults in the first weeks, an apparently healthy population was established which started to reproduce in March. It was the persistence of this population that led us to attempt to "recondition" the tank by slow flushing from the bottom, letting

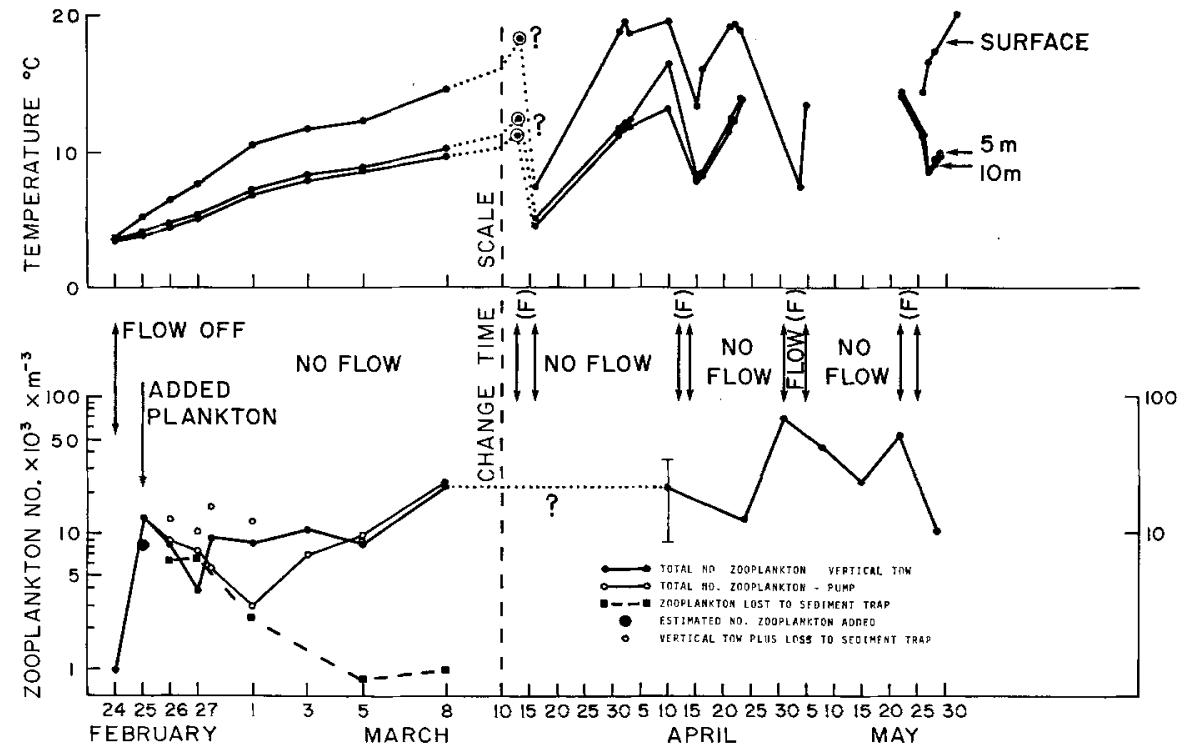

Fig. 6: Changes in temperature and total zooplankton numbers, including also mortality as estimated from sediment trap samples, over a period of 3 months, with tower tank in the non-flow mode, except for four short intervals necessary to recondition the water 


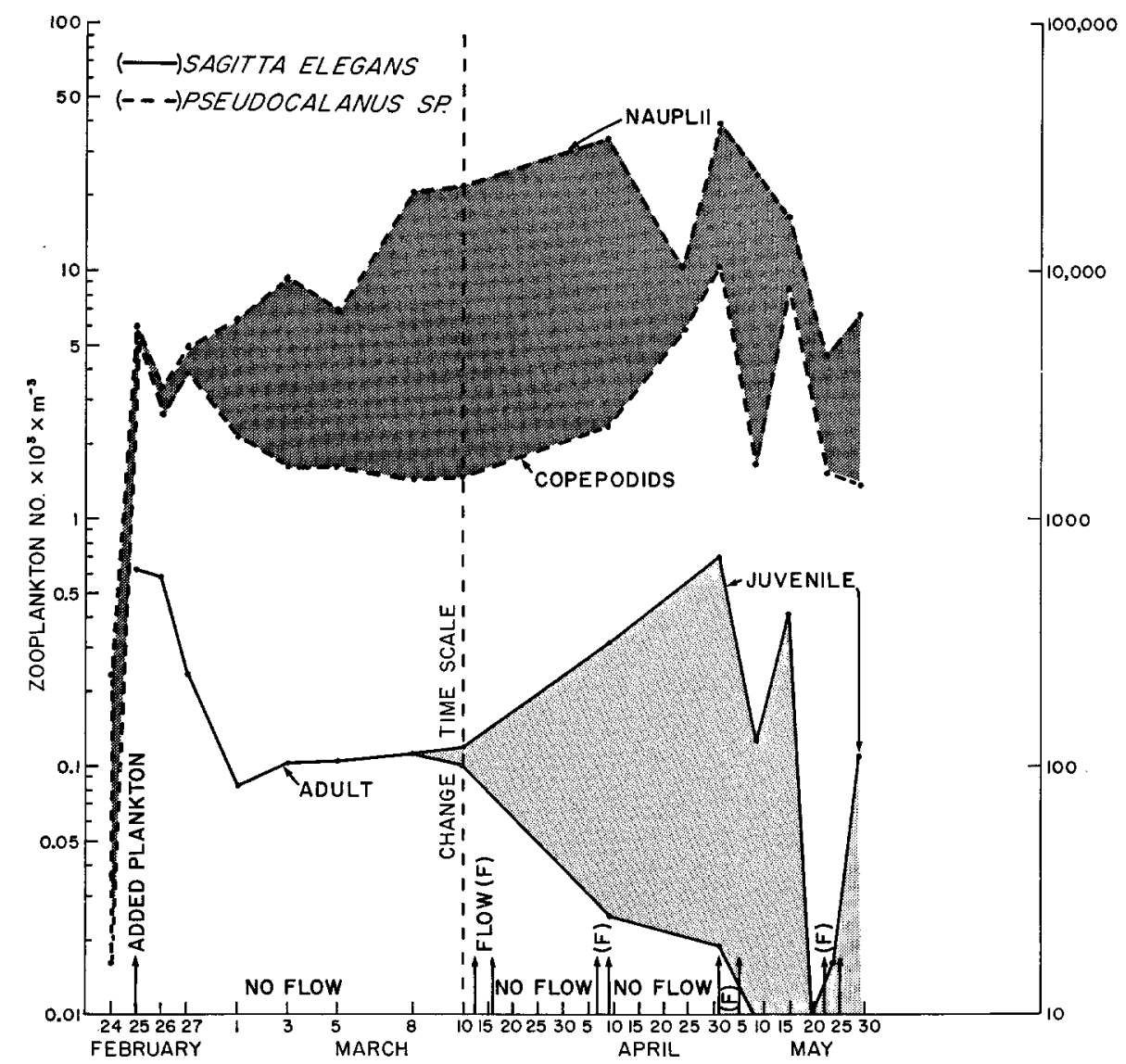

Fig. 7: Changes in the numbers of older and younger stages of the copepod Pseudocalanus sp. and the chaetognath Sagitta elegans over a period of 3 months with the tower tank in the non-flow mode, except for four short intervals necessary to recondition the water

the water run to waste out the top, over four intervals in April and May (Fig. 6). While some animals of all groups were lost in this process and, undoubtedly, a few new ones introduced, none of the populations were seriously depleted and reproduction of young stages maintained total populations at approximately the same level over the entire four-month period.

While Sagitta individuals were visible at all depths in the tank, they tended to stay in the bottom water both "day" and "night". For the most part they seemed to hang vertically in the water, either head up or down, apparently depending on its direction of previous swimming. Short bursts of horizontal swimming were observed regularly but most of the animals remained motionless, and nearly invisible most of the time. No certain attack on a prey organism was observed, perhaps because most feeding occurred at night and in the dark (Pearre, 1973), but we could not clearly establish that there were more individuals with food in the guts at a particular time 
of day. Attempts to observe the animals at night using white light were highly disruptive as Sagitta were strongly attracted to the source of illumination.

In some ways more interesting were observations on the behaviour of the thecosomatous pteropod Spiratella retroversa. In this species, the calcium carbonate shell constitutes about $50 \%$ of the dry weight. If living animals are placed in a sea water aquarium they must swim vigorously or sink rapidly to the bottom, where the majority will be found most of the time; yet in local waters they are largely epiplanktonic. Locomotion with $50 \%$ of your weight in the form of limestone would seem to be prohibitively inefficient energetically for a pelagic animal but in the tower tank, Spiratella did not sink immediately to the bottom nor swim continuously. When the sinking rates of twelve "resting" individuals were measured through the tank ports, the average rate was about $15 \mathrm{~cm} \mathrm{~min}^{-1}$, ranging from 6 to 38 . Vertical upward swimming rates (they were never observed to swim down) were somewhat more variable, averaging around $60 \mathrm{~cm} \mathrm{~min}^{-1}$ with a range from 18 to 120 . Thus to maintain the same relative position in the water column the animals needed to swim about $25 \%$ of their time.

Animals could be observed from the surface of the tank for long periods because they did not so readily sink or swim out of the line of sight as when observed through the ports. A number of animals were watched for period of 10 or more minutes and the duration of sinking and swimming periods measured with a stop watch. The approximate vertical distribution was calculated from the sinking and swimming rates for some representative animals and plotted in Figure 8. Most of the animals apparently remained in the upper 1 metre. In fact, only one individual sank long enough during the period of observation to be lost from view. While pteropods also could be seen at all depths, at least $75 \%$ of the population was always above 4 metres.

How the pteropods regulate their buoyancy is still uncertain. Some, such as members of genera Cavolinia and Diacria, have elongate mantle appendages, with surface area proportional to body weight, that could participate in buoyancy regulation, perhaps helping in the establishment of ionic gradients (Gilmer, 1974). No such appendages occur in the genus Spiratella so far as is known. Instead, the buoyancy regulation appears to be carried out with the wings alone. Figure 9 shows some rough interpretative sketches based on a series of photographs taken through the tank ports of passive or sinking animals. In general, the long axis of the shell is oriented horizontally or nearly so with the aperture up. Some photographic views look directly into the umbo and in such cases the wings were directed up and toward the viewer. Perhaps the angle of the wings made with the horizontal (Figs. $9 \mathrm{~A}, \mathrm{C}$ ) partially regulates the sinking rate. In any event, the observer could usually tell when the pteropod was about to start swimming a few seconds prior because it brought the wings forward over the aperture and started to sink more rapidly. The orientation then was esentially as shown by Morton (1954) in his Figure 1 (6).

Also shown in Figure 9 is a sketch of a faecal string freely floating in the water after becoming detached from the pteropod. Animals in the passive phase are frequently seen to have a faecal string attached, which may be lost when animal starts swimming or occasionally can be seen trailing after a moving individual.

Unfortunately our photographs were not sufficiently clear to see just how the 


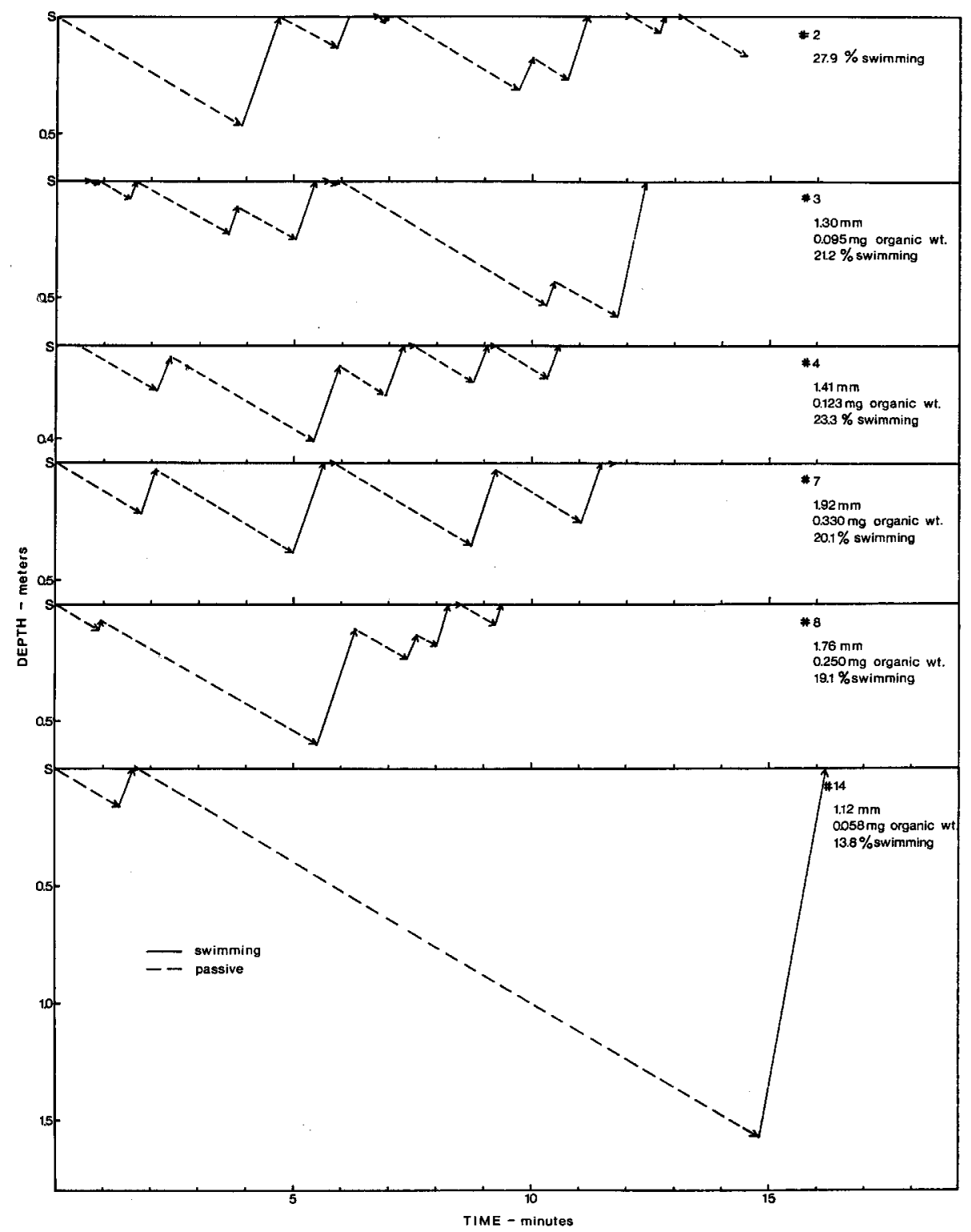

Fig. 8: Periods of swimming and passively sinking and feeding, for some selected individual pteropods Spiratella retroversa with estimated vertical distributions over time 

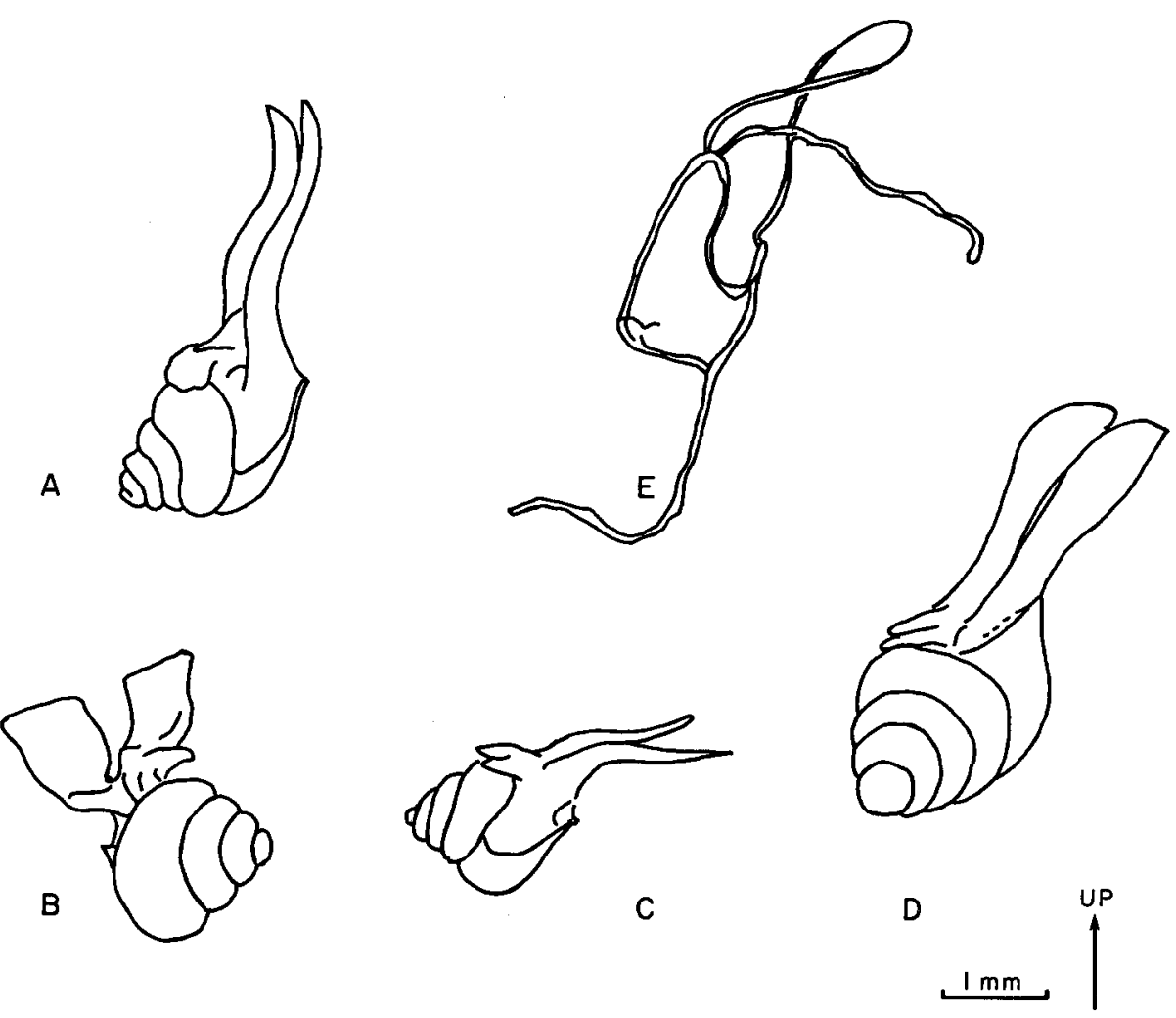

Fig. 9: Characteristic positions of passively sinking and feeding pteropods Spiratella retroversa $(A-D)$, with a free-floating faecal string produced by a feeding Spiratella (E)

foot lobes, presumably important in food gathering, were oriented. Morton (1954) has shown the ciliary currents employed by Spiratella retroversa in food getting, presumably observed in an animal resting on its shell. Our observations suggest that the position of the wings during feeding should be rotated about $90^{\circ}$ away from the axis of curvature in contrast with his Figure 2. Apparently, Spiratella retroversa feeds as it sinks slowly through the water column, generally returning to the surface or to near its original level by periodic bursts of swimming. Thus, the pattern of behaviour seems to differ little from those described by Gilmer (1974) for several tropical thecosomes.

\section{DISCUSSION AND CONCLUSIONS}

A relatively large column of water confined to a cylindical tank seems first to have been used in planktological research at Göteborg, Sweden (Pettersson et al., 1939) and later at La Jolla, California (Strickland et al., 1969). In each case, the tank was used primarily as a large culture vessel in which the water was first purged of its natural community of living organisms insofar as possible and single species or 
groups of cultured phytoplankton introduced secondarily. The Scripps tank has also been used to culture zooplankton but again by adding species to produce a rather simple, three step food chain (Mullin \& Evans, 1974). Pettersson et al. (1939) mentioned that "wild" zooplankton had been kept in the tank successfully, but otherwise there does not seem to have been a previous attempt to establish natural communities in such a system.

Our experience suggests that natural communities can be established in such a water column without major changes in community structure at least at higher trophic levels. Local imbalances or patches of microzooplankton and flagellates were noted with the tank in the static mode, but once the problems of circulation and temperature control have been remedied, perhaps balanced or near-balanced ecosystems may be established and studied. However, the effects of various perturbations on such communities would seem better studied in the more easily replicated plastic water columns (Takahashi et al., 1975).

One other drawback to the establishment of natural pelagic communities in tanks such as that at Dalhousie University would seem to be the fixed intake depth and the long and perhaps damaging residence of water in the plumbing before reaching the tank itself. If the tank could be filled by effectively layering the water from its proper natural depth without seriously affecting the populations contained in it, some interesting possibilities for the study of the microstructure of water columns and their populations would exist.

The greatest advantage of the captive, shore-established water column over those suspended in the sea would seem to be the greater ease with which the behaviour of certain animals can be studied visually while perhaps affording the opportunity to investigate the effects of such behaviour on the environment itself. Perhaps in this way we can achieve something of the success of Hamner et al. (1975) in studying "blue water" communities in situ with Scuba where conditions are too cold or too turbid or both for this approach.

Acknowledgements. The authors are indebted to Drs. C. Boyd and N. Balch and to F. Knipps for their co-operation in the use of the Aquatron. P. Wainwright, M. Lewis and $\mathrm{J}$. Bromley helped in the chemical and biological analyses.

\section{LITERATURE CITED}

Conover, R. J. \& Mayzaud, P., 1976. Respiration and nitrogen excretion of neritic zooplankton in relation to potential food supply. In: Proceedings of the 10th European Symposium on Marine Biology. Ed. by G. Persoone \& E. Jaspers. University Press, Wetteren 2, 191-163.

Gilmer, R. W., 1974. Some aspects of feeding in thecosomatous pteropod molluscs. J. exp. mar. Biol. Ecol. 15, 127-144.

Hamner, W. M., Madin, L. P., Alldredge, A. L., Gilmer, R. W. \& Hamner, P. P., 1975. Underwater observations of gelatinous zooplankton: sampling problems, feeding biology, and behavior. Limnol. Oceanogr. 20, 907-917.

Morton, J. E., 1954. The biology of Limacina retroversa. J. mar. Biol. Ass. U. K. 33, 297-312.

Mullin, M. M. \& Evans, P. M., 1974. The use of a deep tank in plankton ecology. 2. Efficiency of a planktonic food chain. Limnol. Oceanogr. 19, 902-911. 
Pearre, S., Jr., 1973. Vertical migration and feeding in Sagitta elegans Verrill. Ecology 54, 300-314.

Pettersson, H., Gross, F. \& Koczy, F. F., 1939. Large scale plankton culture. Nature, Lond. 144, 332-333.

Siegel, S., 1956. Nonparametric statistics for the behavioral sciences. McGraw-Hill, New York, $312 \mathrm{pp}$.

Strickland, J. D. H., Holm-Hansen, O., Eppley, R. W. \& Linn, R. J., 1969. The use of a deep tank in plankton ecology. I. Studies of the growth and composition of phytoplankton crops at low nutrient levels. Limnol. Oceanogr. 14, 23-34.

Takahashi, M., Thomas, W. H., Seibert, D. L. R., Beers, J., Koeller, P. \& Parsons, T. R., 1975. The replication of biological events in enclosed water columns. Arch. Hydrobiol. 76, 5-23.

Webster, T. J. M., Paranjape, M. A. \& Mann, K. H., 1975. Sedimentation of organic matter in St. Margaret's Bay, Nova Scotia. J. Fish. Res. Bd Can. 32, 1399-1407.

First author's address: Dr. R. J. Conover

Bedford Institute of Oceanography

Dartmouth, Nova Scotia

Canada 